Journal of Neurology, Neurosurgery, and Psychiatry, 1980, 43, 849-852

Short report

\title{
Effects of induced hyperthermia on visual evoked potentials and saccade parameters in normal subjects and multiple sclerosis patients
}

\author{
S BAJADA, F L MASTAGLIA, J L BLACK, AND D W K COLLINS
}

From the Department of Neurology, University Department of Medicine, and the Department of Biophysics, Sir Charles Gairdner Hospital, Perth, Western Australia

SUMMARY A convenient method for raising body temperature has been developed and used to evaluate temperature effects on visual evoked potentials and saccade reaction time and velocity in five normal subjects and five patients with multiple sclerosis.

The value of visual evoked potential (VEP) recording ${ }^{2}$ and quantitative electrooculography $(\mathrm{EOG})^{3-5}$ in the diagnostic evaluation of patients with multiple sclerosis (MS) is well-documented. Both techniques allow subclinical abnormalities to be detected in a significant number of patients. The symptomatic effects of changes in body temperature in MS also are well-known, ${ }^{6-9}$ and the effects of induced hyperthermia on central nervous system conduction in MS have been studied with various electrophysiological techniques. These include electronystagmography, ${ }^{10}$ double-flash discrimination ${ }^{11}$ and VEP recording. ${ }^{12} 13$ We describe a method for raising body temperature which can conveniently be used for neurophysiological studies and present preliminary results of the effects of induced hyperthermia on the pattern VEP and on saccade parameters in normal subjects and MS patients.

\section{Patients and methods}

Five normal volunteers (three females, two males), aged 20 to 28 years, who denied any visual or neurological symptoms and five MS patients who were in a stable state were studied (table).

The subjects, wearing underclothes and hospital cotton gowns, were wrapped inside a "body-bag"

\footnotetext{
Address for reprint requests: Professor FL Mastaglia, University Department of Medicine, Queen Elizabeth II Medical Centre, Nedlands, WA 6009, Australia.
}

Accepted 14 April 1980 (fig 1) and sat in a dental chair. Heating was carried out over a 30 to 45 minute period by blowing hot air through the narrowed lower opening in the bag, using two commercial hair dryers. A combination of heating lamps and immersion in hot water were used for heating in two of the MS subjects (Cases 4 and 5). Oral temperatures were measured with a mercury thermometer at five to ten minute intervals during heating and prior to each test. Temperature rise was $0.7^{\circ}$ $1.5^{\circ} \mathrm{C}$ in the normal subjects and $0.3^{\circ}-1.1^{\circ} \mathrm{C}$ in the MS patients. The procedure was tolerated well but one MS patient complained of nausea and headache, and another of dizziness. None experienced deterioration of vision.

Pattern-reversal VEPs were recorded from an active midline electrode at $\mathrm{Oz}$ (10-20 system) during monocular central field $\left(3^{\circ}\right.$ radius; $12^{\prime}$ checks) stimulation..$^{14}$ The latency and amplitude of the major positive component (P2 or P100) of the VEP were measured. The VEPs were recorded using a similar technique in Cases 4 and 5 who were studied at King's College Hospital, London. ${ }^{2}$ Reaction times and peak velocities for abducting and adducting saccades were measured for each eye in the five normal subjects and three MS patients (Cases 1-3) using a technique described elsewhere. ${ }^{515}$ The VEP and saccade studies were performed before heating and again after completion of the heating procedure. Electrodes for recording the VEP and EOG were positioned securely at the beginning of the study using Grass electrode jelly or collodion. 
Table Details of the five MS patients studied

\begin{tabular}{|c|c|c|c|c|c|c|c|c|c|}
\hline Case & Sex & $\begin{array}{l}\text { Age } \\
(y r)\end{array}$ & $\begin{array}{l}\text { Duration of } \\
\text { disease }\end{array}$ & $\begin{array}{l}\text { Clinical } \\
\text { category }\end{array}$ & $\begin{array}{l}\text { Visual } \\
\text { involvement }\end{array}$ & $\begin{array}{l}\text { Eye } \\
\text { movements }\end{array}$ & $\begin{array}{l}\text { Other } \\
\text { manifestations }\end{array}$ & $\begin{array}{l}\text { Temperature } \\
\text { sensitivity }\end{array}$ & $V E P \dagger$ \\
\hline $1(\mathrm{PI})^{*}$ & F & 26 & $3 \mathrm{yr}$ & CD & - & Bilateral INO & Spinal cord & + & $\begin{array}{l}\text { Abnormal } \\
\text { bilaterally }\end{array}$ \\
\hline $2(\mathrm{SP})^{*}$ & $\mathbf{M}$ & 28 & $4 \mathrm{yr}$ & CD & - & Nystagmus & $\begin{array}{l}\text { Cerebellar and } \\
\text { cord }\end{array}$ & - & Normal \\
\hline $3(\mathrm{CP})^{*}$ & $\mathbf{M}$ & 52 & $4 \mathrm{yr}$ & CD & - & $\begin{array}{l}\mathbf{R} \text { abducens } \\
\text { paresis }\end{array}$ & $\begin{array}{l}\text { Cerebellar and } \\
\text { cord }\end{array}$ & - & Normal \\
\hline $4(\mathrm{JH}) \ddagger$ & $\mathbf{F}$ & 36 & $3 \mathrm{mth}$ & EPL & $\begin{array}{l}\text { R optic } \\
\text { neuropathy; } \\
\text { VA } 6 / 18\end{array}$ & Nystagmus & $\begin{array}{l}\text { Cerebellar and } \\
\text { cord }\end{array}$ & - & Normal \\
\hline 5 (IC) & $\mathbf{F}$ & 61 & $3 \mathrm{mth}$ & EPL & - & Nystagmus & Cord & - & Normal \\
\hline
\end{tabular}

CD - clinically definite MS

EPL - early probable or latent MS (McDonald \& Halliday, 1977) ${ }^{22}$

INO -internuclear ophthalmoplegia

* Patients in whom saccadic reaction times and velocities were measured.

$\dagger$ Visual evoked potentials prior to heating.

‡ Subsequently developed typical relapsing MS.

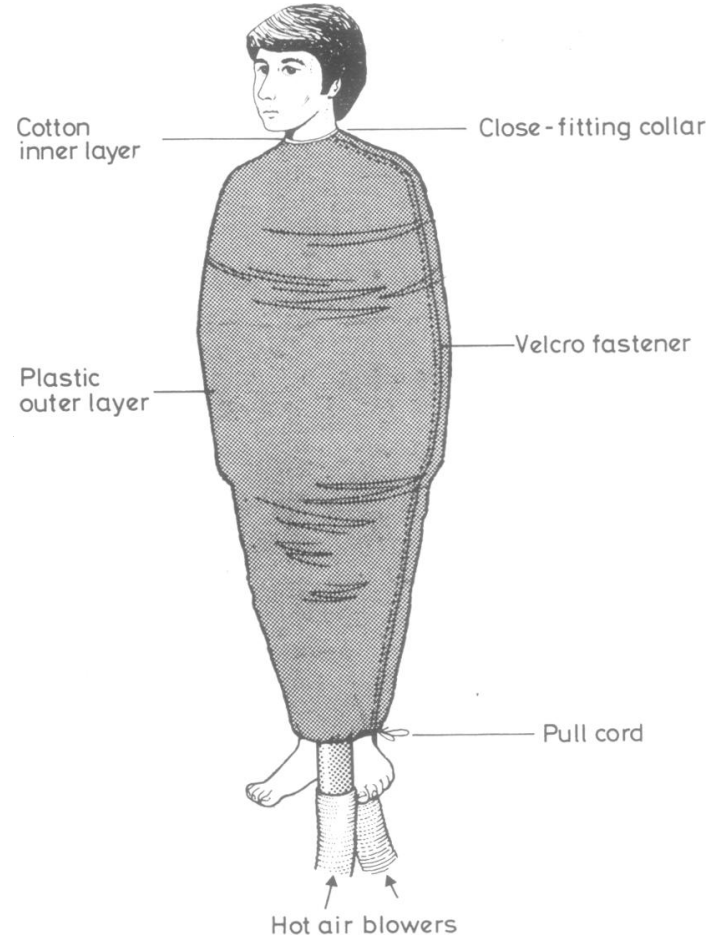

Fig 1 The "body-bag" used for heating.

\section{Results}

Visual evoked potentials In the normal subjects the P2 latency fell by 2 to $6 \mathrm{~ms}$ after heating in six eyes, increased by $2 \mathrm{~ms}$ in one eye and remained unchanged in three eyes (fig $2 \mathrm{~A}$ ). The P2 amplitude fell by $4 \%$ to $26 \%$ in eight eyes, increased by $12 \%$ in one eye, and remained unchanged in one eye after heating (fig 2B).
The VEPs were normal in four of the MS subjects before heating. After heating in these four cases, the P2 latency fell by 2 to $6 \mathrm{~ms}$ in five eyes, and increased by $3 \mathrm{~ms}$ in one eye (fig 2A). P2 amplitude fell by $13 \%$ to $60 \%$ in seven eyes and increased by $26 \%$ to $50 \%$ in three eyes (fig 2B). In each patient the response remained within normal limits after heating. In the fifth patient (Case 1), who had bilaterally delayed VEPs before heating, the right eye latency increased by $8 \mathrm{~ms}$, while the amplitude of the right eye response fell by $28 \%$ and that of the left eye response by $66 \%$ after heating.

Saccadic studies Reaction times and velocities were within the normal range (Mastaglia et al $1979)^{5}$ in each of the normal subjects before heating and showed only minor changes after heating. Reaction times fell by $1 \%-9 \%$ in four patients and rose by $2 \%$ in one patient, while velocities showed changes of $0.1 \%-0.4 \%$ in four patients. Reaction times were abnormal in one of the three MS patients studied (Case 1) and showed increases of $0.5 \%-4 \%$ after heating. Velocities did not change significantly after heating in Case 2, but fell in Cases 1 and 3. In Case 1 , previously normal abducting velocities fell by $27 \%$ and adducting velocities, which were considerably reduced before heating, fell by a further $10 \%$. In Case 3, adducting velocities were normal before heating and fell by $46 \%$ after heating.

\section{Discussion}

The "body-bag" method for heating offers advantages for electrophysiological studies over other methods such as the heat cradle, ${ }^{10}$ humidified "hot-box"8 and hot water immersion."11 16 The method allows ready access to any part of 


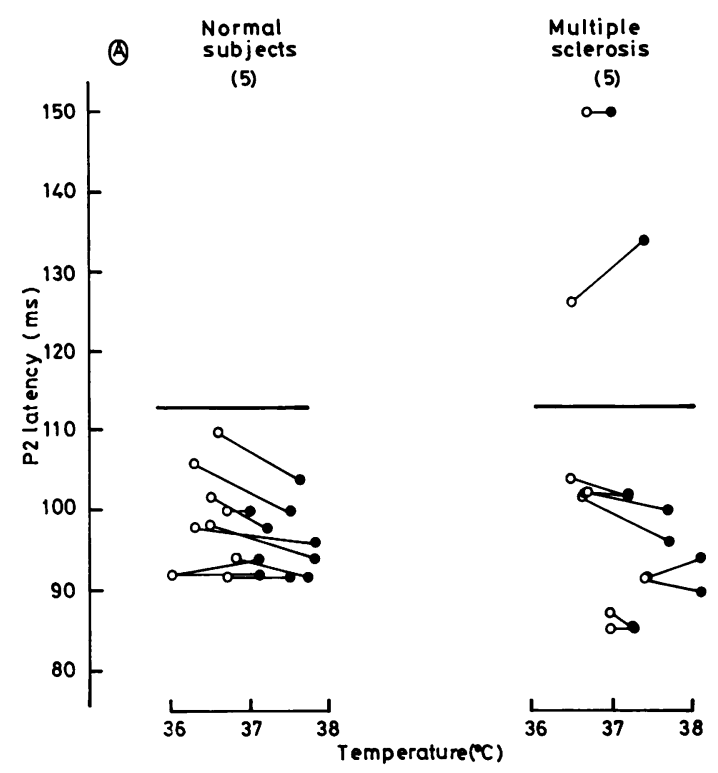

(6)

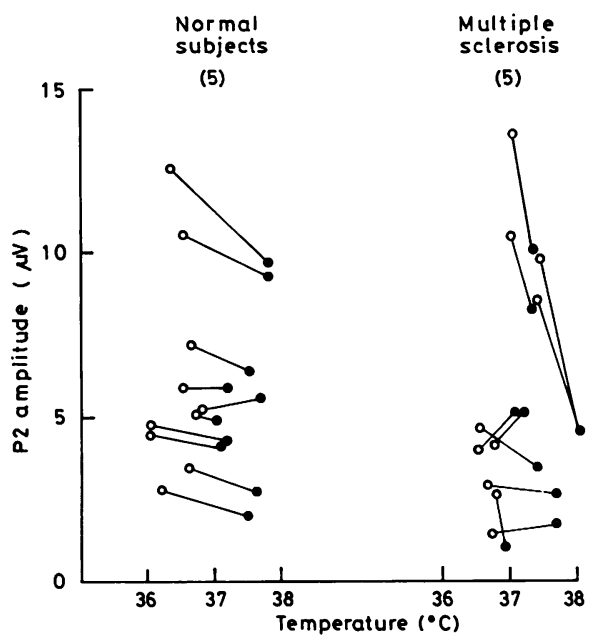

Fig 2 (A) Latencies of the P2 component of the visual evoked potential before (open circles) and after heating (full circles) in normal subjects and $M S$ patients. (B) Amplitude of the P2 component of the visual evoked potential before (open circles) and after heating (full circles) in normal subjects and MS patients.

the body and allows the subject greater freedom of movement.

While the changes in VEP latency in normal subjects after heating were less than $10 \%$ and were not statistically significant, amplitude changes were more marked (reductions of up to $26 \%$ ) as was found by Matthews et al. ${ }^{13}$ Whether such changes are the result of alterations in skin resistance or stimulus perception resulting from temperature effects on the skin or ocular mediae, or result from physiological changes in impulse conduction in the visual pathways remains to be determined. A temperatureinduced reduction in nerve fibre action potential amplitude has been shown in the squid giant axon $^{17}$ and the possibility that an increase of temperature may alter the temporal pattern of impulse transmission or cause conduction block in some nerve fibres in the visual pathway has been considered. ${ }^{13} 18$

Our VEP findings in the MS subjects agree with those of Matthews et al, ${ }^{13}$ who also found a fall in P2 amplitude without significant latency changes after heating. In the present study an appreciable increase in latency occurred in the patient whose VEPs were already delayed before heating, and only minor changes occurred in the other four patients with normal responses. Unlike Matthews et $a l^{13}$ who found a comparable reduction in $\mathbf{P} 2$ amplitude in their normal and MS patients, we found considerably greater amplitude reductions after heating in two of the MS patients than in any of the control subjects. Reduced P2 amplitude and increased latency after heating may be due to changes in conduction in demyelinated nerve fibres in the visual pathway. It is known from experimental work in the peripheral nervous system that conduction in demyelinated fibres is extremely temperature sensitive.1920 Amplitude reduction without latency change would be more readily accounted for by reversible conduction block in demyelinated nerve fibres than by slowing of conduction, which would be more likely to cause a delayed response. Transient VEP amplitude reduction without latency change has also been shown to occur after exercise in some MS patients. ${ }^{21}$

Temperature effects on saccade parameters have not been reported previously. The finding of substantial reductions in saccade velocities after heating in two of the MS patients suggests that conduction in the ocular motor pathway in demyelinating disease is also affected by temperature increase, as in the visual pathway and peripheral nervous system. Reduction in saccadic velocity after heating may result from failure of high-frequency repetitive firing in saccade generator neurones. 


\section{References}

1 Halliday AM, McDonald WI, Mushin J. Visual evoked response in the diagnosis of multiple sclerosis. Br Med J 1975; 4:661-4.

2 Asselman P, Chadwick DW, Marsden CD. Visual evoked responses in the diagnosis and management of patients suspected of multiple sclerosis. Brain 1975; 98:261-82.

3 Bird AC, Leech J. Internuclear ophthalmoplegia. An electro-oculographic study of peak angular saccadic velocities. $\mathrm{Br} J$ Ophthalmol 1976; 60: 645-51.

4 Mastaglia FL, Black JL, Cala LA, Collins DWK. Evoked potentials, saccadic velocities and computerised tomography in diagnosis of multiple sclerosis. Br Med J 1977; 1:1315-7.

5 Mastaglia, FL, Black JL, Collins DWK. Quantitative studies of saccadic and pursuit eye movements in multiple sclerosis. Brain 1979; 102: 817-836.

6 Uhthoff W. Untersuchungen uber die bei der multiplen herdsklerose vorkommenden augenstorungen. Arch Psychiatr und Nervenkr 1890; 21:55-116, 303-410.

7 Watson CW. Effect of lowering of body temperature on the symptoms and signs of multiple sclerosis. New Engl J Med 1959; 261: 1253-9.

8 Namerow NS. Temperature effect on critical flicker fusion in multiple sclerosis. Arch Neurol (Chicago) 1971; 25:269-75.

9 Symington GR, Mackay IR, Currie TT. Improvement in multiple sclerosis during prolonged induced hypothermia. Neurology (Minneapolis) 1977; 27:302-3.

10 Jestico JV, Ellis PDM. Changes in nystagmus on raising body temperature in clinically suspected and proved multiple sclerosis. $\mathrm{Br}$ Med J 1976; 2: 970-2.

11 Galvin RJ, Regan D, Heron JR. A possible means of monitoring the progress of demyelination in multiple sclerosis; effect of body temperature on visual perception of double light flashes.
J Neurol Neurosurg Psychiatry 1976; 39:861-5.

12 Regan D, Murray J, Silver R. Effect of body temperature on visual evoked potential delay and visual perception in multiple sclerosis. $J$ Neurol Neurosurg Psychiatry 1977; 40:1083-91.

13 Matthews WB, Read DJ, Pountney E. Effect of raising body temperature on visual and somatosensory evoked potentials in patients with multiple sclerosis. J Neurol Neurosurg Psychiatry 1979; 42:250-5.

14 Collins DWK, Black JL, Mastaglia FL. Patternreversal visual evoked potentials. Method of analysis and results in multiple sclerosis. J Neurol Sci 1978; 36:83-95.

15 Black JL, Mastaglia FL, Collins DWK. On-line electro-oculography. Int J Bio-med Comput 1978; 9:393-404.

16 Nelson DA, McDowell F. Effects of induced hyperthermia on patients with multiple sclerosis. J Neurol Neurosurg Psychiatry 1959; 22:113-6.

17 Hodgkin AL, Katz B. The effect of temperature on the electrical activity of the giant axon of the squid. J Physiol (London) 1949; 109:240-9.

18 Davis FA, Schauf CL, Reed BJ, Kesler RL. Experimental studies of the effects of extrinsic factors on conduction in normal and demyelinated nerve. J Neurol Neurosurg Psychiatry 1975; 34:275-80.

19 Davis FA, Jacobsen S. Altered thermal sensitivity in injured and demyelinated nerve: a possible model of temperature effects in multiple sclerosis. J Neurol Neurosurg Psychiatry 1971; 34:551-61.

20 Rasminsky M. The effects of temperature on conduction in demyelinated single nerve fibres. Arch Neurol (Chicago) 1972; 28:287-92.

21 Persson HE, Sachs C. Provoked visual impairment in multiple sclerosis studied by visual evoked responses. Electroencephalogr Clin Neurophysiol 1978; 44:664-8.

22 McDonald WI, Halliday AM. Diagnosis and classification of mutiple sclerosis. Brit Med Bull 1977; 33:4-8. 